\title{
Advance care planning in primary care: a retrospective medical record study among patients with different illness trajectories
}

Yvonne A. C. Bekker ${ }^{1}$, Ankie F. Suntjens ${ }^{1}$, Y. Engels ${ }^{2}$, H. Schers ${ }^{3}$, Gert P. Westert ${ }^{1}$ and A. Stef Groenewoud ${ }^{{ }^{*}}$

\begin{abstract}
Background: Advance Care Planning (ACP) enables physicians to align healthcare with patients' wishes, reduces burdensome life-prolonging medical interventions, and potentially improves the quality of life of patients in the last phase of life. However, little objective information is available about the extent to which structured ACP conversations are held in general practice.

Our aim was to examine the documentation of ACP for patients with cancer, organ failure and multimorbidity in medical records (as a proxy for ACP application) in Dutch general practice.

Methods: We chose a retrospective medical record study design in seven primary care facilities. Medical records of 119 patients who died non-suddenly (55 cancer, 28 organ failure and 36 multimorbidity) were analysed. Other variables were: general characteristics, data on ACP documentation, correspondence between medical specialist and general practitioner (GP), and healthcare utilization in the last 2 years of life.

Results: In 65\% of the records, one or more ACP items were registered by the GP. Most often documented were aspects regarding euthanasia (35\%), the preferred place of care and death (29\%) and concerns and hopes towards the future (29\%). Median timing of the first ACP conversation was 126 days before death (inter-quartile range (IQR) 30-316). ACP was more often documented in patients with cancer (84\%) than in those with organ failure (57\%) or multimorbidity (42\%) ( $p=0.000)$. Patients with cancer had the most frequent (median 3 times, IQR $2-5$ ) and extensive (median 5 items, IQR 2-7) ACP consultations.

Conclusion: Documentation of ACP items in medical records by GPs is present, however limited, especially in patients with multimorbidity or organ failure. We recommend more attention for - and documentation of - ACP in daily practice, in order to start anticipatory conversations in time and address the needs of all people living with advanced conditions in primary care.
\end{abstract}

Keywords: Advance care planning, Primary care, General practice, General practitioner, Medical records, End of life care

*Correspondence: stef.groenewoud@radboudumc.nl

${ }^{1}$ Radboud University Medical Center, Radboud Institute for Health

Sciences, Scientific Center for Quality of Healthcare, PO Box 9101, 6500,

$\mathrm{HB}$, Nijmegen, the Netherlands

Full list of author information is available at the end of the article

\section{Key statements}

What is already known:

- Worldwide, the application of Advance Care Planning (ACP) in daily practice is still low.

- Little is known about the actual practice and documentation of $\mathrm{ACP}$ in the GP population, and for different patient groups. 
- Previous studies are either self-reporting, or focus on one specific patient group.

What this paper adds:

- This paper sheds light on the application and documentation of ACP in medical records of GPs.

- We analysed and contrasted the application of ACP for different illness (and EoL) trajectories (cancer, organ failure, multimorbidity).

- This paper examines the application of ACP in primary care in terms of its contents, timing, extensiveness and frequency.

\section{Introduction}

Advance Care Planning (ACP) is the ongoing process of communication among patients, their healthcare providers, family and loved ones regarding health-related problems, needs and preferences for future care $[1,2]$. Timely conversations about these topics enable healthcare providers to align healthcare with the wishes of the patient [3], thereby extending patient autonomy and patient centred care, even when a patient would become unable to participate in decision making due to, for example, cognitive impairment or a crisis situation [4]. ACP is a crucial element of palliative care, which is often indicated when patients suffer from chronic, progressive and life-limiting illnesses [5]. ACP includes items like resuscitation policy, treatment limitations, preferred place of care and death, and conversations about future scenarios $[1,2]$. Positive outcomes of ACP have been reported: ACP is found to improve the quality of end of life (EoL) care. It also reduces unwarranted life-sustaining treatments, it prevents hospitalization in the last months of life, and facilitates access to palliative care and hospice care $[3,6-8]$. Moreover, it decreases the physical and mental burden of relatives and informal caregivers [7] and it may lower healthcare costs [9].

In many Western countries, general practitioners (GPs) play an important role in providing and coordinating palliative care for cancer as well as for non-cancer patients [10]. Also, the long-term relationship between a patient and GP provides a good basis for initiating timely ACP conversations [11]. Therefore, the GP is well positioned to encourage and engage in timely ACP.

However, little is known about the actual application and documentation of ACP in medical records in general practice. Previous studies are mainly based on self-report by GPs [12-15], and documentation has only been studied in a specific GP population of patients with lung and colorectal cancer [16]. Also, patients' personal wishes, concerns, values and beliefs are often left out, though according to recent definitions and recommendations, they are just as much part of ACP as, for example, specific treatment limitations [1].
Our study's first objective is to provide better insight into the practice and (as a proxy for that) the documentation of ACP in medical records of GPs in the Netherlands. Second, we sought to analyse and contrast if the ACP practice differs for several illness trajectories. We hypothesize that in disease categories with a less predictable trajectory (organ failure, multimorbidity) the prevalence and extensiveness of ACP in general practice will be lower. Finally, we also wanted to see how healthcare utilization at the EoL differed in accordance with differences in the ACP practice.

\section{Methods}

\section{Study design, setting and data source}

For this retrospective medical record study, we retrieved data from the Family Medicine Network (FaMe-net), a primary care registration network in Nijmegen, the Netherlands. This network routinely collects patient data from the electronic GP information system (GPIS) of its seven associated general practices. The database included the medical records of all patients who died between 2003 and $2016(n=1235)$. These patient records consisted of: personal characteristics (gender, age at death), reports from the GP, diagnostic ICPC-codes (International Classification of Primary Care), medication prescriptions, correspondence from and to other healthcare providers (of secondary care, out-of-hours primary care and paramedic services) and measured (lab) values, all provided with accompanying dates.

\section{Study population}

First, children (under the age of 18 years) and patients primarily diagnosed with dementia (ICPC-1 P70) were excluded, since both groups form an exception in terms of decisional capacity. Second, a stratified sample of 150 patient records was taken. The number of 150 was chosen, based on relevant literature on the prevalence of disease trajectories at EoL [17]. Besides, we aimed to include at least 30 records per disease category, in order to reach the minimal power for the requested statistical tests. Furthermore, the sample was drawn with an equal distribution among the seven general practices, to reduce the risk of bias, to maintain maximum variation in cases and documentation and to enhance representativity. To compare the application and documentation of ACP in patients with a different trajectory of illness, four groups were created, based on literature: i) patients dying from incurable cancer, whose decline is generally progressive and reasonably predictable, usually with a clear terminal phase $[18,19]$; ii) Patients with organ failure (like respiratory and heart failure), whose decline might be punctuated by episodes of acute deterioration and some recovery, with more sudden, seemingly unexpected death;. iii) 
Elderly with multiple chronic diseases (i.e. multimorbidity) whose decline is often prolonged and gradual [18, 19]; iv) Patients who died suddenly. We used the following inclusion hierarchy: cancer [1], organ failure [2], multimorbidity [3] and acute death [4], meaning that patients who could be classified in more than one category were classified in the first 'fitting' category). Allocation was based on medical history and diagnosis was checked and corrected for registration errors. The 'cancer' group was defined as patients that had a diagnosed active malignancy at the moment of death (concerning mostly patients with metastasized disease). The 'organ failure' group included patients with end-stage heart failure (NYHA 3-4), chronic obstructive pulmonary disease (Gold classification 3-4), renal failure (GFR $<15 \mathrm{ml} /$ min) and symptomatic liver failure. The 'multimorbidity' group was defined as patients aged $\geq 65$ years with multimorbidity, meaning $\geq 2$ chronical diseases other than cancer or end-stage organ failure. The 'acute death' group included the remaining patients, who died unexpectedly without a history of cancer, organ failure or multimorbidity (e.g. suicide or an acute cardiovascular event). Subsequently, the 'acute death' category was excluded, because ACP is less applicable for such patients. Also, files with too limited data for proper group assignment and/or analysis were excluded.

\section{Data collection}

We used patient record information of the last 2 years before death for data extraction. Our rationale was that we expected to find most ACP-related information in the last year(s) of life and that it is recommended to regularly re-discuss ACP themes, especially near the end of life [1]. Also, the widely used surprise question uses a 1-year timeline [20], which we decided to double because we wanted to minimize the risk of missing essential information. We designed a data extraction form to collect quantitative data on patient characteristics and ACP-items (Additional file 1: Appendix 1). In total, 17 ACP-items were defined, based on the recent international consensus on the definition of and recommendations for ACP, supported by the European Association for Palliative Care [1]. A panel discussion with senior investigators (ASG and YE) led to optimization of the form. Then, two researchers (AS and YB) independently collected data from the first nine patient records (three from each group), using the data extraction form. These findings were discussed, which led to final adjustments of the form. No relevant differences between the researchers were found. In this way, inter-observer reliability was considered to be guaranteed, and further in-depth data collection was performed by one researcher (YB).

\section{Variables}

The final data extraction form contained different sections with the following elements (for variables marked with an ", dates (dd/mm/yyyy) were registered):

1. General characteristics: patient ID, practice ID, disease category, gender, date of death, age at time of death, place of death, presence of a written euthanasia request and received EoL treatment (palliative sedation, euthanasia, assisted suicide)

2. Healthcare utilization in the last 2 years of life: number of hospitalizations", number of emergency department visits" and number of contacts with an after-hours primary care center (telephone contacts, consults at the out-of-hours primary care center and home visits) ${ }^{*}$

3. ACP items: documented treatment preferences for future care (regarding resuscitation, mechanical ventilation, intensive care (IC) admission, emergency department referral and hospitalization, antibiotics, artificial feeding and liquid administration and 'other treatment preferences'), preferred place of care and/ or death, registration of advance directives (allocation of a legal representative and a declaration of will) and conversations regarding palliative sedation, euthanasia, prognosis/life expectancy, disease specific future scenarios, personal wishes and goals, concerns and hopes towards the future and the 'end-oflife' or death. We define ACP 'prevalence' as: at least one documented ACP item (out of these 17 items). 'Extensiveness' is the number of documented ACP items. 'Frequency' is the documented number of anticipatory conversations regarding ACP items.

4. ACP characteristics: ACP presence ( $\geq 1$ item documented), timing of first ACP conversation (documentation; in days until death) and frequency (number of ACP conversations, based on the different dates on which ACP items were reported)*

'First ACP conversation' and 'frequency' (number of ACP conversations) concerned discussions of one or more ACP item(s) between a patient (and his/her family or loved ones) and their GP. ACP items were scored if they consisted of proactive, anticipating discussions, registrations or actions (concerning future treatments or situations). We additionally scored ACP-related information that was found in the correspondence from secondary care medical specialists, out-of-hours GPs and paramedics. 'Other treatment preferences', 'preferences for place of care/death', 'personal wishes and goals' and 'concerns and hopes towards future' were extracted as free text for further analysis. 


\section{Data analysis}

Statistical analyses were performed using IBM SPSS Statistics 22. We used descriptive statistics for all outcome measures to describe the current ACP practice (first research objective) as well as the health care utilisation (third objective). The extensiveness of ACP was further categorized in 'no ACP', '1 or 2 items documented', '3-5 items documented' and ' 6 or more items documented'. Differences between the three disease categories (second research objective) were assessed using Pearson's chi-square test or Fischer's exact test (in case $>20 \%$ of the cells had an expected count less than 5) for categorical variables. For continuous variables, we used the ANOVA in case the distribution was normal and the Kruskal Wallis test in case the distribution was skewed. A $P$ value of $<0.05$ was considered significant. In case of significance, we performed post hoc analysis, comparing groups mutually (pairwise) using independent t-tests (or Mann-Whitney U) and Pearson's chi-square tests (or Fisher's exact). A Bonferroni correction was applied, adjusting the level of significance to correct for multiple comparisons [21]. This led to a significance level of $p<0.0167(0.05 / 3)$. Qualitative thematic analysis was applied on the extracted free text that had been entered in the files by GPs. We applied an open coding technique [22] that was simultaneously performed by two researchers (YB and AS), who discussed codes together and reached consensus on both codes and themes. Emerging themes were used to illustrate and underpin results.

\section{Results}

Study sample

After the selection of 150 records, and applying the exclusion criteria, medical records of 119 patients who died non-suddenly were identified for the in-depth file research, of whom 55 patients with cancer, 28 with organ failure and 36 with multimorbidity (see flowchart in Fig. 1).

\section{Patient characteristics and general information about the last 2 years of life}

The mean age of the patients at time of death was 79years (range: 27-103; see Table 1). Patients with cancer were younger than patients with organ failure and multimorbidity (both $p=0.000$ ). The male:female ratio was approximately 1:1 for all groups. Most patients died at home (59\%). Other places of death were hospital (27\%), hospice (5\%), and long-term care facility (3\%).

All patients who died in a hospice were patients with cancer. Most patients who died in a hospital had multimorbidity (44\%) or cancer (34\%). Prevalence of (intermittent or continuous) palliative sedation was highest in the cancer group (40\%), followed by the multimorbidity (22\%) and the organ failure group (7\%). Ten patients (8\%) had a documented written euthanasia directive. Euthanasia was actually performed in $50 \%$ of those patients, who all had cancer. More than two thirds of the patients visited the emergency department (70\%) and were hospitalized $(72 \%)$ at least once in the last 2 years of life. The median numbers of hospitalizations, emergency

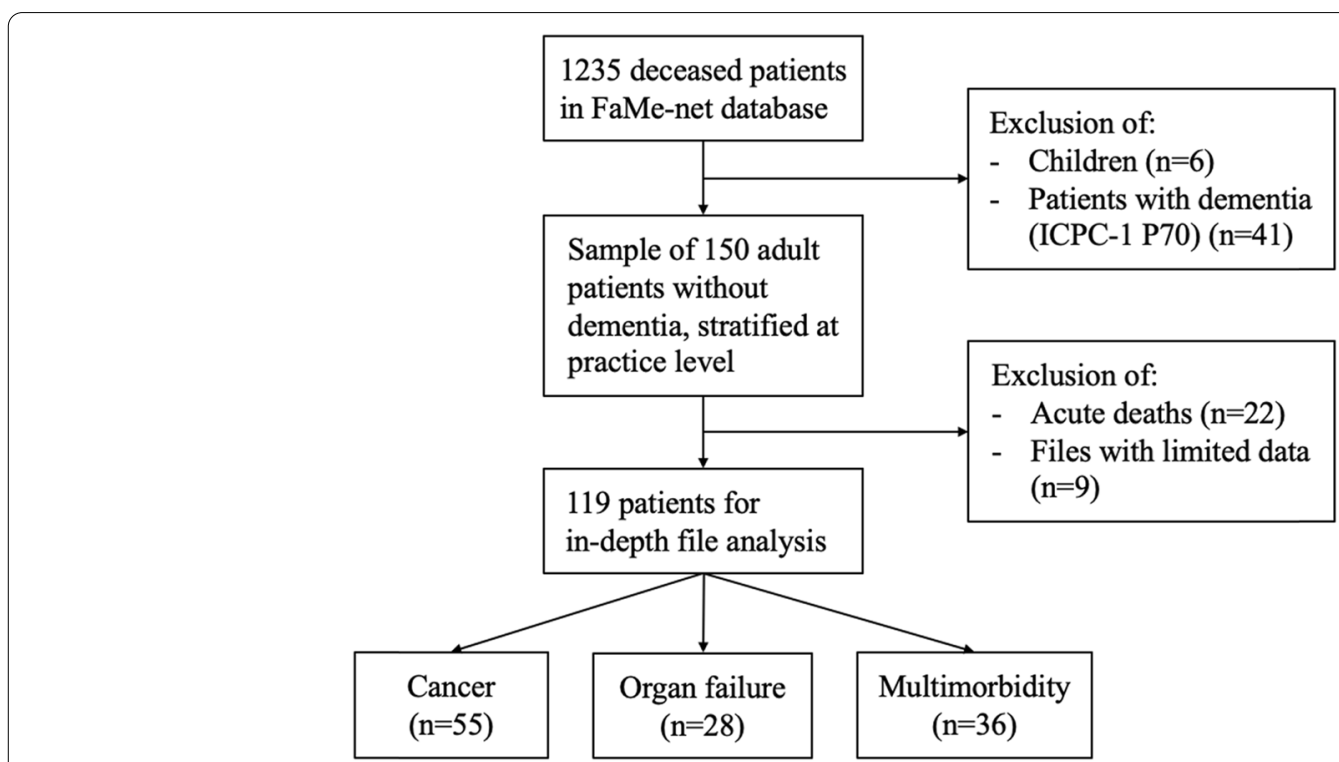

Fig. 1 Selection of patients who died non-suddenly of 'cancer', 'organ failure' or 'multimorbidity' in general practice 
Table 1 Patient characteristics and healthcare use in the last two years of life (subgroup analyses for cancer, organ failure and multimorbidity patients)

\begin{tabular}{|c|c|c|c|c|c|}
\hline General characteristics & $\begin{array}{l}\text { Total } \\
(n=119)\end{array}$ & $\begin{array}{l}\text { Cancer } \\
(n=55)\end{array}$ & $\begin{array}{l}\text { Organ failure } \\
(n=28)\end{array}$ & $\begin{array}{l}\text { Multimorbidity } \\
(n=36)\end{array}$ & $P$ value \\
\hline Gender female, n (\%) & $61(51)$ & $29(53)$ & $14(50)$ & $18(50)$ & $0.957^{*}$ \\
\hline Age at time of death, mean (SD) & $79(14)$ & $70(14)$ & $84(8)$ & $88(7)$ & $0.000^{* *}$ \\
\hline Place of death, $n(\%)$ & & & & & $0.088^{* * *}$ \\
\hline Home & $70(59)$ & $35(64)$ & $16(57)$ & $19(53)$ & \\
\hline Hospital & $32(27)$ & $11(20)$ & $7(25)$ & $14(39)$ & \\
\hline Hospice & $6(5)$ & $6(11)$ & $0(0)$ & $0(0)$ & \\
\hline Long-term care facility & $4(3)$ & $1(2)$ & $1(4)$ & $2(6)$ & \\
\hline Unknown & $7(6)$ & $2(4)$ & $4(14)$ & $1(3)$ & \\
\hline \multicolumn{6}{|l|}{ EoL support, n (\%) } \\
\hline Palliative sedation & $32(27)$ & $22(40)$ & $2(7)$ & $8(22)$ & $0.005^{*}$ \\
\hline Euthanasia/assisted suicide & $5(4)$ & $5(9)$ & $0(0)$ & $0(0)$ & $0.085^{* * *}$ \\
\hline \multicolumn{6}{|c|}{ Healthcare use, median (25th-75th percentile, range) } \\
\hline Number of hospitalizations & $1(0-3,0-15)$ & $2(1-3,0-11)$ & $2(1-4,0-15)$ & $0,5(0-1,0-4)$ & $0.000^{* *}$ \\
\hline Number of ED visits & $1(0-2,0-9)$ & $1(0-3,0-6)$ & $2(1-3,0-9)$ & $1(0-1,0-6)$ & $0.006^{* *}$ \\
\hline Number of GP out of office hours contacts & $1(0-4,0-22)$ & $1(0-4,0-22)$ & $2(0-5,0-6)$ & $1(0-2,0-8)$ & $0.316^{* *}$ \\
\hline
\end{tabular}

department visits, and out-of-hours primary care contacts are shown in Table 1.

\section{Application of ACP}

Prevalence of ACP ( $\geq 1$ item documented) by the GP in the last 2 years of life was $65 \%$. In $40 \%$ of all medical records, three or more items were registered, and in $18 \%$ six or more items. The prevalence differed significantly between the three groups, with respectively 84,57 and $42 \%$ in patients with cancer, organ failure and multimorbidity $(p=0.000)$ (see Table 2$)$. Post hoc analyses showed that ACP was applied more often in the cancer group than in the organ failure and multimorbidity group $(p=0.015$ and $\mathrm{p}=0.000$ respectively). There was no statistically significant difference between the organ failure and multimorbidity group $(p=0.314)$. The prevalence of ACP also differed between practices $(p=0.030)$, as some of the practices had a higher prevalence than others (range 42-83\%).

If ACP was applied (at least one item documented), the frequency (median number of ACP conversations) was three, with a median of four different items that were documented. The extent (number of ACP items documented) and frequency (number of ACP conversations) of ACP differed significantly between the groups ( $p=0.047$ and $p=0.012$, respectively). Post hoc analyses (Table 3 ) showed that the number of consultations in which ACP was documented was significantly higher in patients with cancer than in patients with multimorbidity $(p=0.010)$. All other post hoc analyses did not show a statistically significant difference. The median time period from the first ACP documentation until death was 126 days (interquartile range (IQR) 30-316), with no significant difference between patient groups. IQRs showed a large variation in timing in all three disease groups.

The prevalence of ACP for all patients and for the different disease categories is visualized in Fig. 2. The colours in the bars represent the number of ACP items discussed.

\section{Content of ACP}

If aspects of ACP were documented by a GP, this most often regarded: euthanasia (35\%), preferred place of care and death (29\%), concerns and hopes towards the future (29\%), prognosis (24\%) and palliative sedation (23\%) (see Table 4).

Most often documented treatment preferences were resuscitation policy (21\%) and policy for referral and hospitalization (19\%). 'Other treatment preferences' consisted mostly of disease specific treatment choices for future care, such as chemotherapy, follow-up diagnostics, surgical procedures and medication choices or limitations (other than antibiotics). The items 'personal wishes and goals' and 'hopes and concerns towards the 
Table 2 Prevalence and characteristics of Advance Care Planning by GP (subgroup analyses for cancer, organ failure and multimorbidity patients)

\begin{tabular}{|c|c|c|c|c|c|}
\hline Prevalence of ACP (documentation) & $\begin{array}{l}\text { Total } \\
(n=119)\end{array}$ & $\begin{array}{l}\text { Cancer } \\
(n=55)\end{array}$ & $\begin{array}{l}\text { Organ failure } \\
(n=28)\end{array}$ & $\begin{array}{l}\text { Multimorbidity } \\
(n=36)\end{array}$ & $P$ value \\
\hline Prevalence ( $\geq 1$ ACP item), n (\%) & $77(65)$ & $46(84)$ & $16(57)$ & $15(42)$ & $0.000^{*}$ \\
\hline Characteristics of ACP & $\begin{array}{l}\text { Total } \\
(n=77)\end{array}$ & $\begin{array}{l}\text { Cancer } \\
(n=46)\end{array}$ & $\begin{array}{l}\text { Organ failure } \\
(n=16)\end{array}$ & $\begin{array}{l}\text { Multimorbidity } \\
(n=15)\end{array}$ & $P$ value \\
\hline \multicolumn{6}{|l|}{ Extent } \\
\hline $\begin{array}{l}\text { Number of ACP items, median (25th - } 75 \text { th } \\
\text { percentile, range) }\end{array}$ & $4(2-7,1-11)$ & $5(2-7,1-11)$ & $3,5(2-6,1-8)$ & $2(1-5,1-7)$ & $0.047^{* *}$ \\
\hline Subclassification: & & & & & $0.222^{* * *}$ \\
\hline Low (1 or 2 items) & $29(38)$ & $15(33)$ & $6(38)$ & $8(53)$ & \\
\hline Medium ( 3,4 or 5 items) & $26(34)$ & $14(30)$ & $6(38)$ & $6(40)$ & \\
\hline High ( $\geq 6$ ACP items) & $22(29)$ & $17(37)$ & $4(25)$ & $1(7)$ & \\
\hline \multicolumn{6}{|l|}{ Frequency } \\
\hline $\begin{array}{l}\text { Number of ACP conversations, median (25th- } \\
\text { 75th percentile, range) }\end{array}$ & $3(1-4,1-14)$ & $3(2-5,1-14)$ & $2(1-3,1-7)$ & $2(1-3,1-4)$ & $0.012^{* *}$ \\
\hline \multicolumn{6}{|l|}{ Timing } \\
\hline $\begin{array}{l}\text { Time between first ACP conversation and death } \\
\text { in days, median ( } 25 \text { th- } 75 \text { th percentile, range) }\end{array}$ & $126(30-316,1-714)$ & $106(22-307,3-680)$ & $227(39-395,1-714)$ & $113(52-320,10-529)$ & $0.417^{* *}$ \\
\hline
\end{tabular}

* Chi Square test, ${ }^{* *}$ Kruskal Wallis test, ${ }^{* * *}$ Fisher's Exact test

Table 3 Post-hoc tests on differences between groups of patients

\begin{tabular}{llll}
\hline P values of post-hoc analyses & Cancer vs Organ failure & Cancer vs multimorbidity & $\begin{array}{l}\text { Organ failure vs } \\
\text { multimorbidity }\end{array}$ \\
\hline Prevalence ( $\geq 1$ ACP item documented) & $0.015^{*}$ & $0.000^{*}$ & $0.314^{*}$ \\
Extent (number of ACP items) & $0.417^{* * * *}$ & $0.023^{* * * *}$ & $0.175^{* * * *}$ \\
Frequency (number of ACP conversations) & $0.043^{* * * *}$ & $0.010^{* * * *}$ & $0.520^{* * * *}$ \\
\hline
\end{tabular}

* Chi Square test

***** Mann Whitney U test

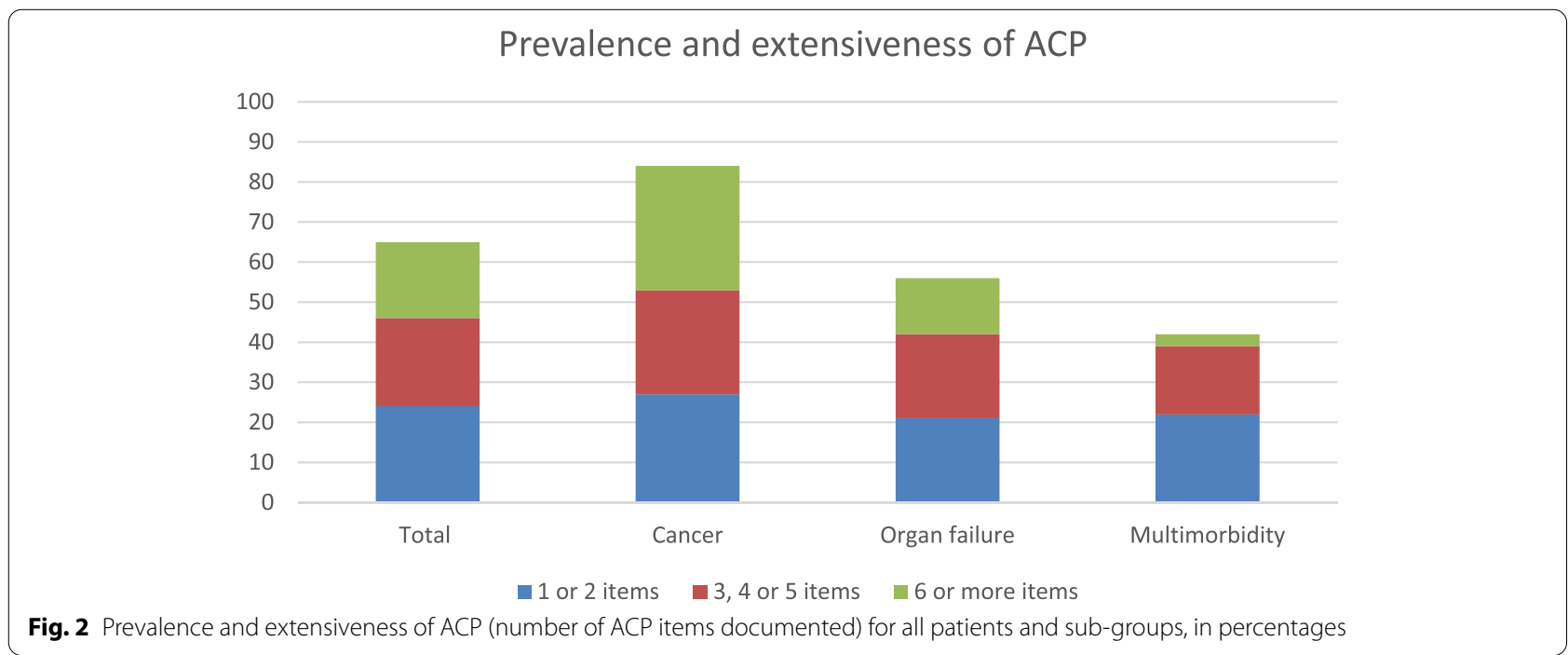


Table 4 ACP content as documented by GPs (subgroup analyses for cancer, organ failure and multimorbidity patients)

\begin{tabular}{|c|c|c|c|c|c|}
\hline Items of ACP & $\begin{array}{l}\text { Total } \\
(n=119)\end{array}$ & $\begin{array}{l}\text { Cancer } \\
(n=55)\end{array}$ & $\begin{array}{l}\text { Organ failure } \\
(n=28)\end{array}$ & $\begin{array}{l}\text { Multimorbidity } \\
(n=36)\end{array}$ & $P$ value \\
\hline \multicolumn{6}{|c|}{ Documented treatment preferences for future care, $\mathrm{n}(\%)$} \\
\hline Resuscitation & $25(21)$ & $11(20)$ & $11(39)$ & $3(8)$ & 0.009 \\
\hline Mechanical ventilation & $2(2)$ & $2(4)$ & $0(0)$ & $0(0)$ & 0.499 \\
\hline Intensive Care Unit admission & $4(3)$ & $2(4)$ & $2(7)$ & $0(0)$ & 0.266 \\
\hline Referral to ED and hospitalization & $22(19)$ & $8(15)$ & $8(29)$ & $6(17)$ & 0.286 \\
\hline Antibiotics & $4(3)$ & $2(4)$ & $1(4)$ & $1(3)$ & 1.000 \\
\hline Artificial feeding and liquid administration & $1(1)$ & $1(2)$ & $0(0)$ & $0(0)$ & 1.000 \\
\hline Other treatment preferences & $18(15)$ & $11(20)$ & $4(14)$ & $3(8)$ & 0.308 \\
\hline \multicolumn{6}{|l|}{ Documented EoL wishes, n (\%) } \\
\hline Preferred place of care/death & $35(29)$ & $20(36)$ & $7(25)$ & $8(22)$ & 0.327 \\
\hline Personal wishes/goals & $18(15)$ & $16(29)$ & $1(4)$ & $1(3)$ & 0.000 \\
\hline \multicolumn{6}{|l|}{ Discussed future scenarios, n (\%) } \\
\hline Prognosis/life expectancy & $29(24)$ & $18(33)$ & $8(29)$ & $3(8)$ & 0.024 \\
\hline Disease specific future scenarios & $20(17)$ & $16(29)$ & $3(11)$ & $1(3)$ & 0.002 \\
\hline Concerns and hopes towards future & $34(29)$ & $20(36)$ & $7(25)$ & $7(19)$ & 0.206 \\
\hline Conversation about palliative sedation & $27(23)$ & $22(40)$ & $4(14)$ & $1(3)$ & 0.000 \\
\hline Conversation about euthanasia & $42(35)$ & $35(64)$ & $2(7)$ & $5(14)$ & 0.000 \\
\hline Conversation 'end-of-life' & $22(19)$ & $14(26)$ & $5(18)$ & $3(8)$ & 0.136 \\
\hline \multicolumn{6}{|l|}{ Registered advance directives, n (\%) } \\
\hline Declaration of will & $19(16)$ & $18(33)$ & $0(0)$ & $1(3)$ & 0.000 \\
\hline Appointment of legal representative & $0(0)$ & $0(0)$ & $0(0)$ & $0(0)$ & - \\
\hline
\end{tabular}

future' mainly concerned themes related to the different domains of palliative care, i.e. psychological, social and spiritual issues. Examples of personal wishes and goals were: attending specific future events (like the graduation of a grandson or a holiday with family); spending more time outside in the last months of life; regaining enough energy to receive visitors; being able to carry out personal hobbies (like gardening or etching) and the wish for conversations with a chaplain or pastor. Regarding hopes and concerns towards the future, patients mainly expressed their fears, such as cognitive impairment, being a burden to others, being left alone or death itself. Patients hoped, for example, for passing away naturally in the short term. In $19 \%$ of the cases, it was documented that the GP and patient had had a conversation about the 'end-of-life', without further documenting an outcome or specific preferences. When going through the patient records, we noticed that GPs often used loose terms when documenting about ACP, for example: 'conversation about death', 'best supportive care, 'palliative policy' or 'prefers quality instead of quantity'. Also, place of care and death were mostly unseparated, and some patients did not specify their preference, but only discussed which options they did not prefer. Registration of a declaration of will was present in $8 \%$ of the cases. The appointment of a legal representative was never documented.

\section{Impact of ACP on actual care (utilisation)}

Discussion of particular aspects of ACP seems to be associated with the actual (utilisation of) care. When documented (29\%), the preferred place of care/death was 'home' in 57\% and 'hospice' in 26\% of the cases. If GPs discussed and documented the patient's preferred place of care/death, more patients died in a hospice $(p=0.010)$. When the GP and patient had at least one conversation about palliative sedation, more patients were supported by palliative sedation in the last days of life $(p=0.000)$. Documentation of a policy for referral and hospitalization did not influence the number of Emergency Room (ER) visits $(p=0.838)$ and hospitalizations $(p=0.793)$.

\section{Exchanging ACP information with other health care professionals}

GPs also received ACP-related information from other healthcare providers (see Table 5). In 50\% of the medical records, at least one ACP item was found in the correspondence between other healthcare providers and GPs. This concerned mainly resuscitation (28\%) and Intensive Care Unit (ICU) admission (17\%) policies and discussion of prognosis/life expectancy (21\%). All other items had a lower prevalence (0-11\%).

In both the GP and the other healthcare provider documentation, all of the ACP topics showed the highest 
Table 5 Content of ACP in correspondence of other healthcare provider (subgroup analyses for cancer, organ failure and multimorbidity patients)

\begin{tabular}{|c|c|c|c|c|c|}
\hline Items of ACP & $\begin{array}{l}\text { Total } \\
(n=119)\end{array}$ & $\begin{array}{l}\text { Cancer } \\
(n=55)\end{array}$ & $\begin{array}{l}\text { Organ failure } \\
(n=28)\end{array}$ & $\begin{array}{l}\text { Multimorbidity } \\
(n=36)\end{array}$ & $P$ value \\
\hline \multicolumn{6}{|c|}{ Documented treatment preferences for future care, n (\%) } \\
\hline Resuscitation & $33(28)$ & $16(29)$ & $11(39)$ & $6(17)$ & 0.129 \\
\hline Mechanical ventilation & $9(8)$ & $7(13)$ & $1(4)$ & $1(3)$ & 0.150 \\
\hline Intensive Care Unit admission & $20(17)$ & $9(16)$ & $9(32)$ & $2(6)$ & 0.019 \\
\hline Referral to ED and hospitalization & $7(6)$ & $3(6)$ & $3(11)$ & $1(3)$ & 0.470 \\
\hline Antibiotics & $0(0)$ & $0(0)$ & $0(0)$ & $0(0)$ & - \\
\hline Artificial feeding and liquid administration & $1(1)$ & $1(2)$ & $0(0)$ & $0(0)$ & 1.000 \\
\hline Other treatment preferences & $13(11)$ & $9(16)$ & $3(11)$ & $1(3)$ & 0.119 \\
\hline \multicolumn{6}{|l|}{ Documented EoL wishes, n (\%) } \\
\hline Preferred place of care/death & $11(9)$ & $8(15)$ & $1(4)$ & $2(6)$ & 0.272 \\
\hline Personal wishes/goals & $5(4)$ & $4(7)$ & $1(4)$ & $0(0)$ & 0.199 \\
\hline \multicolumn{6}{|l|}{ Discussed future scenarios, $\mathrm{n}(\%)$} \\
\hline Prognosis/life expectancy & $25(21)$ & $21(38)$ & $3(11)$ & $1(3)$ & 0.000 \\
\hline Disease specific future scenarios & $13(11)$ & $11(20)$ & $1(4)$ & $1(3)$ & 0.017 \\
\hline Concerns and hopes towards future & $5(4)$ & $4(7)$ & $0(0)$ & $1(3)$ & 0.439 \\
\hline Conversation about palliative sedation & $4(3)$ & $3(6)$ & $1(4)$ & $0(0)$ & 0.358 \\
\hline Conversation about euthanasia & $8(7)$ & $6(11)$ & $1(4)$ & $1(3)$ & 0.319 \\
\hline Conversation 'end-of-life' & $2(2)$ & $2(4)$ & $0(0)$ & $0(0)$ & 0.499 \\
\hline
\end{tabular}

prevalence rate in the 'cancer' group, with exception of the resuscitation, hospital referral and ICU-admission policy, which were documented most frequently in the 'organ failure' group.

In $24 \%$ of the patients, no ACP items were found in both the GP's file and the correspondence of other healthcare providers.

\section{Discussion}

We found a prevalence of documented ACP activities during the last 2 years of life in GPs' medical records of patients with cancer, organ failure or multimorbidity of $65 \%$. However, the extensiveness of documented ACP was limited, as in $71 \%$ five or less ACP items were covered, and in $38 \%$ only one or two (out of 17 ). Concluding that, in the total population, in the majority of patients ACP was not or only minimally (one or two items) documented $(71 / 119,60 \%)$. For most patients who received $\mathrm{ACP}$, the first ACP conversation took place during the last months of life (median 126 days before death) and the median frequency (number of ACP conversations) was three. Documented ACP mainly focused on euthanasia, concerns and hopes towards the future and the preferred place of care and death. Remarkably, a resuscitation policy was noted by the GP in only $21 \%$, and other treatment preferences and disease specific future scenarios were documented even less, while these are topics that play an important role in case of acute deterioration.
In half of the patients, GPs also received ACP information through the correspondence from other healthcare providers. In such cases, the main ACP aspects concerned resuscitation policy (28\%), prognosis $(21 \%)$ and ICU admission (17\%). Other treatment decisions that take place in the hospital context (such as (dis)continuation of chemotherapy) were scarcely found. In $24 \%$ of the patients, no ACP items were found in both the GPs' file and the correspondence of other healthcare providers.

Application and documentation of ACP differed significantly between the disease categories. The prevalence of ACP was higher in patients with cancer (84\%) than in those with organ failure (57\%) or multimorbidity (42\%). We also found statistically significant differences between the disease categories regarding the number of ACPitems and consultations in which ACP was discussed, with cancer rating highest on both aspects.

\section{Strengths and limitations}

To the best of our knowledge, this was the first study that seeked to explore actual ACP documentation in the population of non-acute deaths in the Dutch general practice, while discerning between different illness (and EoL) trajectories. We picked up on the recent shift in extending ACP also to non-physical issues, as physical changes are usually accompanied by psychological, social and existential fluctuations in the well-being of patients and their families, seen in both cancer as well as non-cancer 
patients [23]. We were able to define $17 \mathrm{ACP}$ items, covering the physical, psychosocial and spiritual dimension, based on the consensus definition and recommendations for ACP supported by the European Association for Palliative Care and expert opinion. By taking a stratified sample that equally represents seven different practices, we enhanced the representativity of our results and minimized the influence of between-practice differences on the found group differences. FaMe-net also aims to be representative of the national population by age, gender and cause of death. Last, our study protocol comprises several check-points to enhance inter-observer reliability (reproducibility).

Also, some limitations must be acknowledged. First, scanned documents, attached to the medical record, were missing from the database, which might explain the low percentage of advance directives and the absence of information on the appointment of legal representatives. Second, data were collected in general practices from a practice-based research network, which are known to have a better registration routine than average. This may have resulted in an overestimation of ACP documentation. On the other hand, participating practices were not specialized in palliative care, and no specific codes for $\mathrm{ACP}$ registration are used in the network. Third, there is a risk of missing ACP related information, as ACP discussions might have taken place without documentation. However, registration of ACP content is essential to facilitate future decision-making that is based on a patient's preferences and is, therefore, a condition to successful ACP, especially since in most health care settings multiple caregivers are involved. Fourth, we may have also missed information by only looking at the last 2 years of life. In our opinion, though, information dating from longer than this period is less relevant as patients' preferences and wishes possibly change along with changes in their medical condition [24]. This is why ACP should be frequently re-discussed [1]. Lastly, our sample contains files from a broad time period up until 2016. Although the majority of the files $(80 / 119)$ dates from the most recent period (2014-2016), this prohibits us from drawing firm conclusions about the current situation.

\section{Interpretation}

Our finding that $35 \%$ of the deceased patients seemed not to have received any form of ACP consultation by their GP and $60 \%$ not or only minimally (one or two items documented), is in line with existing literature about the uptake of ACP in general practice, and may be explained by some barriers for ACP that have been reported before (see Table 6). Recently, patient records in the general practice were examined in Scotland, showing that $60 \%$ of all patients who died in 2014 had an anticipatory care plan; $75 \%$ of the patients with cancer and $41 \%$ with organ failure [25]. Though this was a study in a different country, these percentages are quite comparable with our findings. Ermers et al. found that, in the Netherlands, in $74 \%$ of the records of patients with colorectal and lung cancer, at least one ACP item was documented, compared to $84 \%$ in our group of patients with an active malignancy at the moment of death [16].

Second, our finding that ACP is more prevalent among cancer patients, is in line with the results of other studies $[12-14,25,26]$. Although these studies are based on questionnaires and interviews, whereas our study has the design of a medical record study, existing literature strengthens our conclusion that patients with organ failure and multimorbidity receive less ACP. This might be due to prognostic uncertainty; the relative unpredictability of non-cancer patients' decline possibly impedes physicians to anticipate palliative care needs and initiate end-of-life conversations timely [27]. As there are less direct causes to start the conversations, GPs might prevaricate or postpone when considering end-of-life issues, also described in literature as prognostic paralysis [28]. Also, the need for ACP is often less clear when there is no strict demarcation between the curative and the palliative phase [29]. Patients suffering from cancer are more aware of the life-threatening consequences of their disease and engage in ACP more proactively [30], while patients still

Table 6 Barriers for the uptake of ACP, as reported in the literature

Despite the fact that there is increasing attention for ACP and a growing body of evidence of its positive effects, research shows that the application of ACP conversations remains still low, and the organization and delivery of healthcare is still predominantly reactive [11-16].

Several barriers have been reported that may prevent optimal implementation in clinical practice. First, on the patient-side, participation is at risk in case patients are not ready to talk about themes related to deterioration in their condition or the nearing death [41]. Second, for GPs, insufficient time is among the most important barriers. Third, GPs find it difficult to engage in end-of-life conversations, which is sometimes caused by lack of skills or experience, and that they have a hard time finding the appropriate moment to initiate ACP [27, 31, 33, 42]. Fourth, illness trajectories differ a lot from patient (group) to patient (group). In patients with incurable cancer, the decline is generally progressive and reasonably predictable, usually with a clear terminal phase $[18,19]$. Patients dying from a non-malignant cause, however, frequently experience a more gradual decline. In those with organ failure (like respiratory and heart failure), the decline might be punctuated by episodes of acute deterioration and some recovery, with more sudden, seemingly unexpected death. In the elderly with multiple chronic diseases (i.e. multimorbidity) the decline is often prolonged and gradual [18, 19]. Especially in case of uncertainty of prognosis, there are less clear-cut'triggers' that may help GPs to initiate ACP conversations [31]. 
being treated in the hospital are less open to ACP discussions, as was reported by GPs in earlier research [31]. Nonetheless, ACP is also appropriate alongside optimal chronic disease management and has been widely recommended for non-cancer patients [1, 14, 20, 32]. GPs, however, appear to find this difficult to implement $[20,27,29$, 31-34], resulting in non-cancer patients being relatively underserved with regard to comprehensive and timely ACP.

Third, our results support earlier findings that ACP is initiated late in the disease process; other studies found a timing of ACP that ranged from 33 days until 18 weeks before death, compared to 126 days before death in our study $[16,25,29,35]$.

\section{Implications and recommendations}

Though ACP receives more and more attention, widespread implementation in clinical practice stays behind. A higher prevalence of ACP, broader discussion of ACPrelated themes and timely initiation could benefit the quality of end-of-life care. It appears desirable to close the gap between patients with and without cancer and offer ACP to all patient groups, especially when considering the growing number of old people suffering and dying from serious chronic diseases [36]. Extending an anticipatory care approach to all people with advanced chronic conditions is a challenge and multiple barriers (see Table 6) need to be overcome. Professionals caring for people with life-limiting conditions need core generic skills to enable them to assess supportive care needs and judge the readiness of individual patients and families to participate in discussions about the future. However, many physicians feel poorly prepared to conduct endof-life conversations [37]. Recently, in the Netherlands, $\mathrm{ACP}$ training programs have been developed, such as the course 'Timely end of life conversations' by the Dutch GP Association and the RADPAC training [34]. These trainings might serve as useful aids to educate physicians and to help them deal with feelings of uncertainty, though they are not widely implemented yet. Also, GPs have been appointed as key-players in ACP in the recently launched Quality Framework for Palliative Care in the Netherlands, which may also further improve the uptake of ACP in primary care [38]. Another starting point for improvement is the structure of documentation. Our study shows that there is no uniform structure in registering ACP information in the Netherlands, and we found that both GPs and medical specialists used heterogenous and a specific terminology, which makes it hard to retrieve, transfer and update information. This could be improved by using predictable, homogeneous and exchangeable formats to document ACP, which has been shown to be successful in other countries [25, 39]. Also, a distinction should be made between preferred place of care and preferred place of death, as these do not always have the same outcome [40]. Lastly, timely recognition of patients that could benefit from ACP is essential, but appears to be difficult. In the group of organ failure, hospital admissions and exacerbations might serve as a helpful starting points for discussion about wishes and needs $[23,31]$. We recommend that future research contributes to the identification of patients that may benefit from $\mathrm{ACP}$, as well as the appropriate timing to initiate $\mathrm{ACP}$ conversations.

\section{Conclusion}

This study shows that at least one ACP -item is documented in the medical record in a majority of deceased patients in the Dutch general practice. However, there is considerable potential for improvement in the documentation (and practice) of ACP, concerning the amount of topics covered, disease specific future scenarios and treatment preferences, timely initiation, and the documentation structure and multidisciplinary information exchange. Also, attention is needed for the current gap between patients with cancer and patients with other chronic diseases, addressing the needs of all people living with advanced conditions in primary care.

\section{Abbreviations}

ACP: Advance Care Planning; EoL: End of Life; ED: Emergency Department; GP: General Practitioner; GPIS: General Practitioner's Information System; ICU: Intensive Care Unit; RADPAC: RADboud indicators for PAlliative Care.

\section{Supplementary Information}

The online version contains supplementary material available at https://doi. org/10.1186/s12904-022-00907-6.

Additional file 1: Appendix 1. Data extraction form

\section{Authors' contributions}

YAB performed data extraction, data analyses, wrote a preliminary version of the manuscript, and was involved in later editorial rounds. AS helped designing the study, the data extraction form and helped YAB in performing analyses as well as with writing the first draft of the paper. She was also involved in later editorial activities. YE was one of the supervisors, who also helped developing the data extraction form; she was also involved in writing the article. HS gathered and delivered the FameNet health record data, that formed the basis for this study. He was also involved in writing the article. GW supervised the study and was actively involved in writing all versions of the manuscript. ASG designed the study, acquired the grant, performed daily supervision of YAB and $A S$, and took the initiative in writing the first and later versions of the current article. All authors have read and approved both the initial, and this revised version of the manuscript.

Funding

This study was funded by the Dutch institute for Health Care Research and Sciences (ZonMw), grant number: 844001510. 


\section{Availability of data and materials}

The datasets generated during and analyzed during the current study are not publicly available for reasons of privacy. They are however available (fully anonymised) from the corresponding author on reasonable request.

\section{Declarations}

\section{Ethics approval and consent to participate}

All methods were performed in accordance with the Declaration of Helsinki and with other relevant guidelines and regulations.

The research ethics committee of the Radboud University Medical Center (Radboudumc) Nijmegen declared that this study does not fall within the remit of the Medical Research Involving Human Subjects Act (file number 2018-4271, July 2018). Besides, they approved utilization of the FaMe-Net database for this purpose (file number 2020-6871).

In the participating practices of the FaMe-Net database, all medical ethical and privacy requirements in relation to scientific studies are met. Informed consent was signed by all cooperating general practices and consent of patients was obtained through an opt-out arrangement, to make the data available for quality improvement and research purposes. Patient records were received pseudonymized, whilst the key to the personal data was inaccessible for the researchers.

\section{Consent for publication}

This manuscript does not contain any individual person's data in any form.

\section{Competing interests}

The authors declare that they have no competing interests

\section{Author details}

${ }^{1}$ Radboud University Medical Center, Radboud Institute for Health Sciences, Scientific Center for Quality of Healthcare, PO Box 9101, 6500, HB, Nijmegen, the Netherlands. ${ }^{2}$ Department of Anesthesiology, Radboud University Medical Center, Pain and Palliative Medicine, Nijmegen, the Netherlands. ${ }^{3}$ Department of Primary and Community Care, Radboud University Medical Center, Nijmegen, the Netherlands.

Received: 7 June 2021 Accepted: 24 January 2022

Published online: 14 February 2022

\section{References}

1. Rietjens JAC, Sudore RL, Connolly M, van Delden JJ, Drickamer MA, Droger $\mathrm{M}$, et al. Definition and recommendations for advance care planning: an international consensus supported by the European Association for Palliative Care. Lancet Oncol. 2017;18(9):e543-e51.

2. UpToDate. Advance care planning and advance directives 2018 [Available from: https://www.uptodate.com/contents/advance-care-planning-andadvance-directives.

3. Houben CHM, Spruit MA, Groenen MTJ, Wouters EFM, Janssen DJA. Efficacy of advance care planning: a systematic review and meta-analysis. J Am Med Dir Assoc. 2014;15(7):477-89.

4. Silveira MJ, Kim SY, Langa KM. Advance directives and outcomes of surrogate decision making before death. N Engl J Med. 2010;362(13):1211-8.

5. World Health Organization. Definition of palliative care 2002 [Available from: https://www.who.int/cancer/palliative/definition/en/.

6. Brinkman-Stoppelenburg A, Rietjens JA, van der Heide A. The effects of advance care planning on end-of-life care: a systematic review. Palliat Med. 2014;28(8):1000-25.

7. Detering KM, Hancock AD, Reade MC, Silvester W. The impact of advance care planning on end of life care in elderly patients: randomised controlled trial. BMJ. 2010:340:c1345.

8. Baker A, Leak P, Ritchie LD, Lee AJ, Fielding S. Anticipatory care planning and integration: a primary care pilot study aimed at reducing unplanned hospitalisation. Br J Gen Pract. 2012;62(595):e113-20.

9. Klingler C. In der Schmitten J, Marckmann G. does facilitated advance care planning reduce the costs of care near the end of life? Systematic review and ethical considerations. Palliat Med. 2016;30(5):423-33.
10. Groot MM, Vernooij-Dassen MJ, Crul BJ, Grol RP. General practitioners (GPs) and palliative care: perceived tasks and barriers in daily practice. Palliat Med. 2005;19(2):111-8.

11. Michiels E, Deschepper R, Van Der Kelen G, Bernheim JL, Mortier F, Vander Stichele R, et al. The role of general practitioners in continuity of care at the end of life: a qualitative study of terminally ill patients and their next of kin. Palliat Med. 2007;21(5):409-15.

12. Evans N, Pasman HR, Donker GA, Deliens L, Van den Block L, Onwuteaka-Philipsen B. End-of-life care in general practice: a crosssectional, retrospective survey of 'cancer,', 'organ failure' and 'old-age/ dementia' patients. Palliat Med. 2014;28(7):965-75.

13. Meeussen K, Van den Block L, Echteld M, Bossuyt N, Bilsen J, Van Casteren $\mathrm{V}$, et al. Advance care planning in Belgium and the Netherlands: a nationwide retrospective study via sentinel networks of general practitioners. J Pain Symptom Manag. 2011;42(4):565-77.

14. Abarshi E, Echteld M, Donker G, Van den Block L, Onwuteaka-Philipsen $B$, Deliens L. Discussing end-of-life issues in the last months of life: a nationwide study among general practitioners. J Palliat Med. 2011;14(3):323-30

15. Meeussen K, Van den Block L, Bossuyt N, Bilsen J, Echteld M, Van Casteren $V$, et al. GPs' awareness of patients' preference for place of death. Br J Gen Pract. 2009;59(566):665-70.

16. Ermers DJM, van Bussel KJH, Perry M, Engels Y, Schers HJ. Advance care planning for patients with cancer in the palliative phase in Dutch general practices. Fam Pract. 2019;36(5):587-93.

17. Murray SA, Sheikh A. Care for all at the end of life. BMJ. 2008;336(7650):958.

18. Murray SA, Kendall M, Boyd K, Sheikh A. Illness trajectories and palliative care. BMJ. 2005;330(7498):1007-11.

19. Lunney JR, Lynn J, Foley DJ, Lipson S, Guralnik JM. Patterns of functional decline at the end of life. JAMA. 2003:289(18):2387-92.

20. Gott M, Gardiner C, Small N, Payne S, Seamark D, Barnes S, et al. Barriers to advance care planning in chronic obstructive pulmonary disease. Palliat Med. 2009;23(7):642-8.

21. Midway S, Robertson M, Flinn S, Kaller M. Comparing multiple comparisons: practical guidance for choosing the best multiple comparisons test. Bioinform Genom Dec. 2020;4:2020 https://peerj.com/articles/ 10387/.

22. Hsieh HF, Shannon SE. Three approaches to qualitative content analysis. Qual Health Res. 2005;15(9):1277-88.

23. Murray SA, Kendall M, Grant E, Boyd K, Barclay S, Sheikh A. Patterns of social, psychological, and spiritual decline toward the end of life in lung cancer and heart failure. J Pain Symptom Manag. 2007;34(4):393-402.

24. Auriemma CL, Nguyen CA, Bronheim R, Kent S, Nadiger S, Pardo D, et al. Stability of end-of-life preferences: a systematic review of the evidence. JAMA Intern Med. 2014;174(7):1085-92.

25. Tapsfield J, Hall C, Lunan C, McCutcheon H, McLoughlin P, Rhee J, et al. Many people in Scotland now benefit from anticipatory care before they die: an after death analysis and interviews with general practitioners. BMJ Support Palliat Care. 2019;9(4):e28.

26. Evans N, Costantini M, Pasman HR, Van den Block L, Donker GA, Miccinesi $\mathrm{G}$, et al. End-of-life communication: a retrospective survey of representative general practitioner networks in four countries. J Pain Symptom Manage. 2014;47(3):604-19 e3.

27. De Vleminck A, Pardon K, Beernaert K, Deschepper R, Houttekier D, Van Audenhove C, et al. Barriers to advance care planning in cancer, heart failure and dementia patients: a focus group study on general practitioners' views and experiences. PLoS One. 2014:9(1):e84905.

28. Murray SA, Boyd K, Sheikh A. Palliative care in chronic illness. BMJ. 2005:330(7492):611-2.

29. Claessen SJ, Francke AL, Engels Y, Deliens L. How do GPs identify a need for palliative care in their patients? An interview study. BMC Fam Pract. 2013;14:42

30. Parker SM, Clayton JM, Hancock K, Walder S, Butow PN, Carrick S, et al. A systematic review of prognostic/end-of-life communication with adults in the advanced stages of a life-limiting illness: patient/caregiver preferences for the content, style, and timing of information. J Pain Symptom Manag. 2007;34(1):81-93.

31. Wichmann AB, van Dam H, Thoonsen B, Boer TA, Engels Y, Groenewoud AS. Advance care planning conversations with palliative patients: looking through the GP's eyes. BMC Fam Pract. 2018;19(1):184. 
32. Janssen DJA, Spruit MA, Schols J, Wouters EFM. A call for high-quality advance care planning in outpatients with severe COPD or chronic heart failure. Chest. 2011;139(5):1081-8.

33. De Vleminck A, Houttekier D, Pardon K, Deschepper R, Van Audenhove C, Vander Stichele R, et al. Barriers and facilitators for general practitioners to engage in advance care planning: a systematic review. Scand J Prim Health Care. 2013;31(4):215-26.

34. Thoonsen B, Groot M, Verhagen S, van Weel C, Vissers K, Engels Y. Timely identification of palliative patients and anticipatory care planning by GPs: practical application of tools and a training programme. BMC Palliat Care. 2016;15:39.

35. Mack JW, Cronin A, Keating NL, Taback N, Huskamp HA, Malin JL, et al. Associations between end-of-life discussion characteristics and care received near death: a prospective cohort study. J Clin Oncol. 2012;30(35):4387-95.

36. Barnett K, Mercer SW, Norbury M, Watt G, Wyke S, Guthrie B. Epidemiology of multimorbidity and implications for health care, research, and medical education: a cross-sectional study. Lancet. 2012;380(9836):37-43.

37. Block SD. Medical education in end-of-life care: the status of reform. J Palliat Med. 2002:5(2):243-8

38. the Netherlands Quality Framework for Palliative Care. https://palliaweb. nl/publicaties/netherlands-quality-framework-for-palliative-care

39. Ali AA, Adam R, Taylor D, Murchie P. Use of a structured palliative care summary in patients with established cancer is associated with reduced hospital admissions by out-of-hours general practitioners in Grampian. BMJ Support Palliat Care. 2013;3(4):452-5.

40. Agar M, Currow DC, Shelby James TM, Plummer J, Sanderson C, Abernethy Preference AP. For place of care and place of death in palliative care: are these different questions? Palliat Med. 2008;22(7):787-95.

41. Piers RD, van Eechoud IJ, Van Camp S, Grypdonck M, Deveugele M, Verbeke NC, et al. Advance care planning in terminally ill and frail older persons. Patient Educ Couns. 2013;90(3):323-9.

42. Howard M, Bernard C, Klein D, Elston D, Tan A, Slaven M, et al. Barriers to and enablers of advance care planning with patients in primary care: survey of health care providers. Can Fam Physician. 2018;64(4):e190-e8.

\section{Publisher's Note}

Springer Nature remains neutral with regard to jurisdictional claims in published maps and institutional affiliations.

Ready to submit your research? Choose BMC and benefit from:

- fast, convenient online submission

- thorough peer review by experienced researchers in your field

- rapid publication on acceptance

- support for research data, including large and complex data types

- gold Open Access which fosters wider collaboration and increased citations

- maximum visibility for your research: over $100 \mathrm{M}$ website views per year

At BMC, research is always in progress.

Learn more biomedcentral.com/submissions 